\title{
Prescribed Fire Costs on Juniper-Infested Rangeland
}

\author{
Rob Mitchell, Carlton Britton, Brent Racher, Ernest Fish, and Erin Atkinson
}

$\mathrm{W}$ hat are the true costs of prescribed fire on juniper infested rangelands? Redberry juniper is a basal sprouting, multistemmed evergreen tree growing on rocky slopes with shallow soils. cost of burning, but are often overlooked or difficult to estimate without experience. Texas Tech University has 30 years of experience conducting burns for producers in Texas, New Mexico, and Oklahoma. This experience is applied to 3 examples which illustrate the across the pasture. We considered this a smooth terrain pasture. Pasture $2(2,844$ acres) is located 90 miles from the campus, with rugged terrain in the southwest half of the pasture, but was gently rolling in the northeast half of the pasture. We considered this a mixed terrain

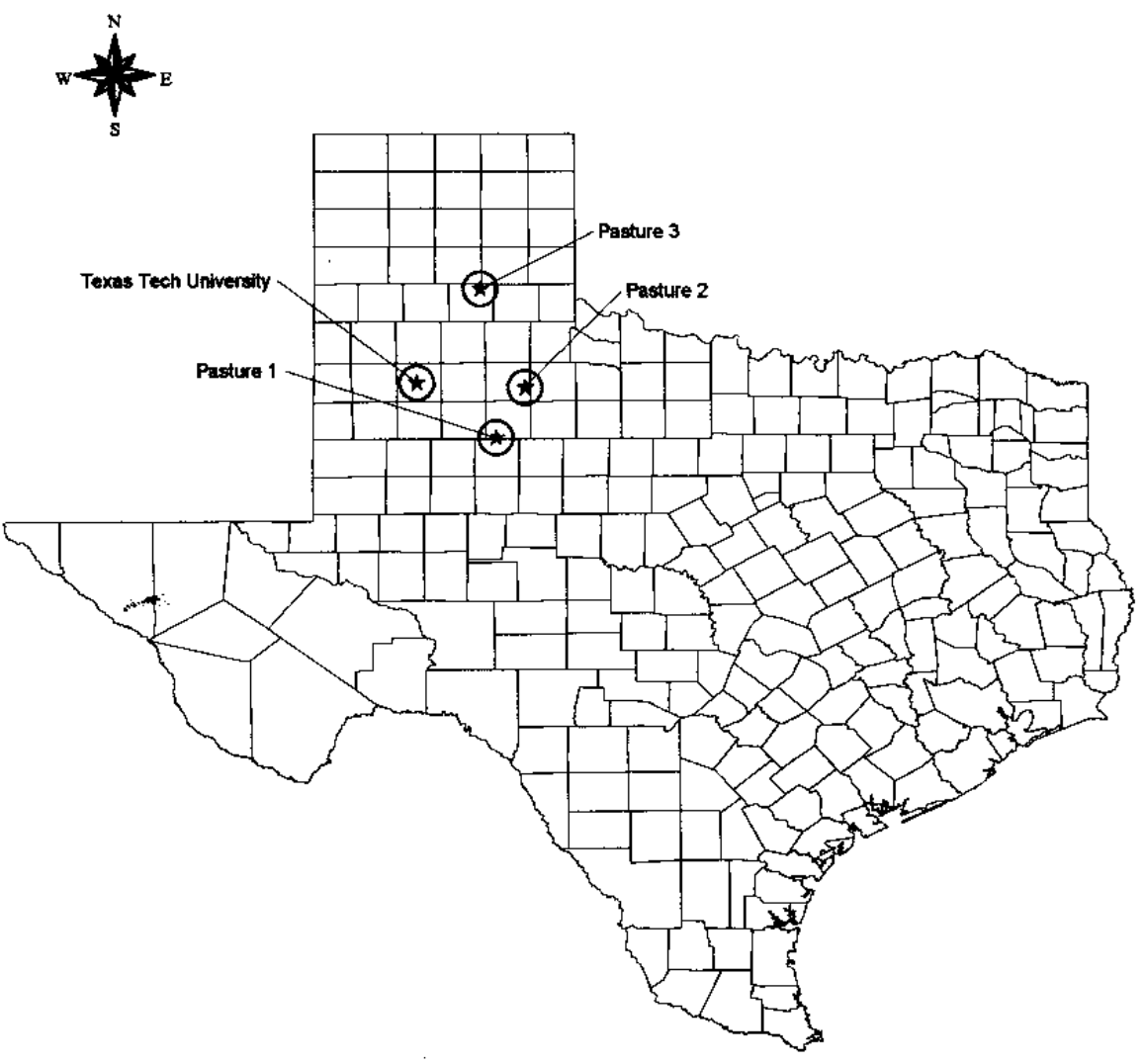

Fig. 1. Map of the pasture locations in Texas.

Although several options are available for managing redberry juniper, prescribed fire is considered the least expensive. Many professionals recommend the application of prescribed fire without knowledge of the actual total costs. Individuals considering contract burning for producers have no guidelines for estimating costs. Factors such as total labor hours, miles driven, torch fuel, and food costs influence the actual total costs for applying prescribed fire. The pastures used were infested by redberry juniper and burned in the spring 1998 (Fig. 1). These pastures represented a spectrum of pastures capable of being ignited from the ground with drip torches.

Pasture 1 (1397 acres) is located 100 miles from the Texas Tech University campus, and had the least broken terrain with the smallest elevation changes pasture. Pasture 3 (2,965 acres) is 140 miles from the campus, was uniformly rugged, and had rockier soil than Pasture 2. We considered this a mixed terrain pasture. The primary difference between Pastures 2 and 3 was the lack of smooth terrain on the north and east sides to apply blacklines in Pasture 3.

Costs recorded during burning included number of workers, total labor hours, miles traveled, torch fuel used, and food 


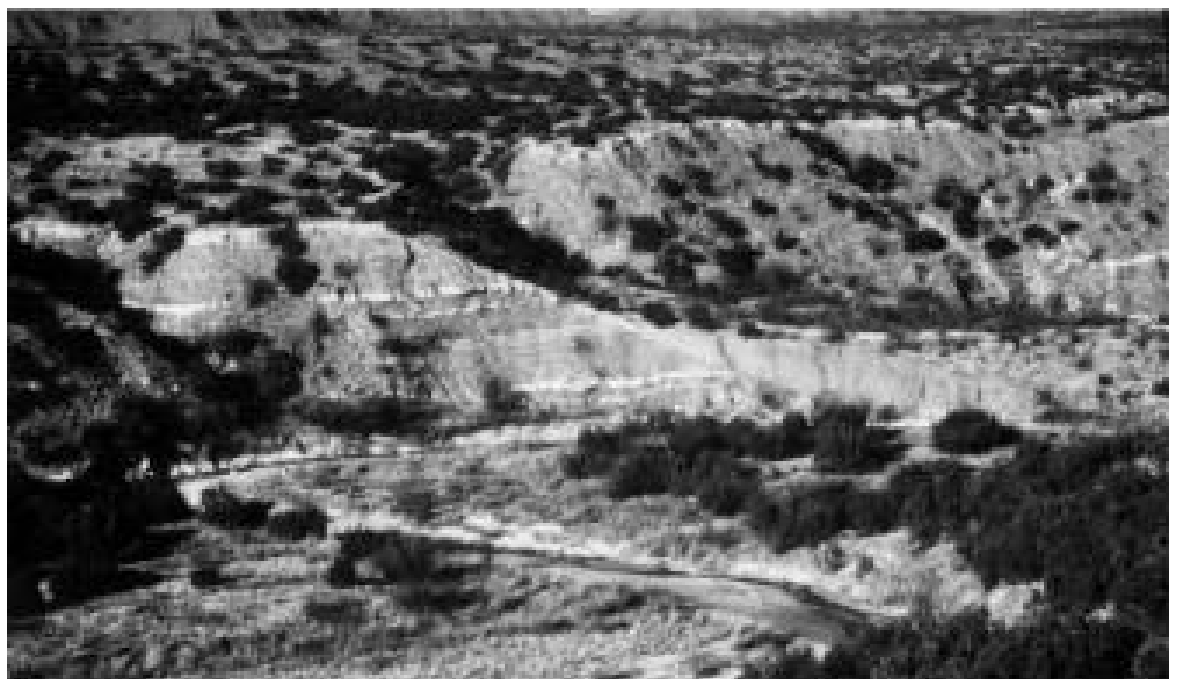

Redberry juniper has invaded many areas in Texas.

cost. Labor was calculated at $\$ 7.00$ per hour, mileage at $\$ 0.27$ per mile, and torch fuel at $\$ 1.02$ per gallon. Torch fuel was mixed as $70 \%$ diesel and $30 \%$ unleaded gasoline. No cost was monitored for dozer work required for fireline preparation (but were estimated), grazing deferment for fine fuel accumulation, and no equipment costs were amortized for the burns. Equipment used to conduct burns at all locations included: a 1-ton, 4-wheel drive truck with a 200 gallon suppression unit and mobile radio, a 3/4-ton, 4-wheel drive truck with a 100 gallon suppression unit and mobile radio, a 12 passenger van, a $250 \mathrm{cc}$, 4-wheeler with a 14-gallon rearmounted sprayer, 14 drip torches, 12 hand-held radios, five backpack sprayers, four belt weather kits, four fire rakes, four McLeods, four swatters, two axes, two chainsaws, and matches. Dozed lines were installed around the perimeter of each pasture and an interior line was installed parallel to the perimeter line on the north and east sides of the burn units. The 500 to 1,000 foot area between the perimeter line and the interior dozed lines was burned to provide blacklines for safely igniting headfires with prevailing southwest winds. Crossover lines were installed in the blacklines at Ç to å mile intervals. The fenced acreage of the pasture containing the Pasture 2 burn unit exceeded 6,000 acres and the north dozed line was installed in a mesquite flat to simplify the burning of the remaining 2,844 acres. The terrain of Pasture 3 required installing many interior lines to facilitate burning the pasture in several units.

\section{Pasture Comparison}

The cost to burn the pastures ranged from $\$ 3.07$ to $\$ 6.15 /$ acre (Table 1). Cost to burn the pastures averaged $\$ 4.39$ /acre without any equipment amortization or dozed line construction costs. It is often assumed that as burn size increases, the cost per acre decreases. This was not the case for these pastures. The distance traveled, travel time, presence of suitable areas within the pasture to locate blacklines, and roughness of the pasture were the primary factors influencing

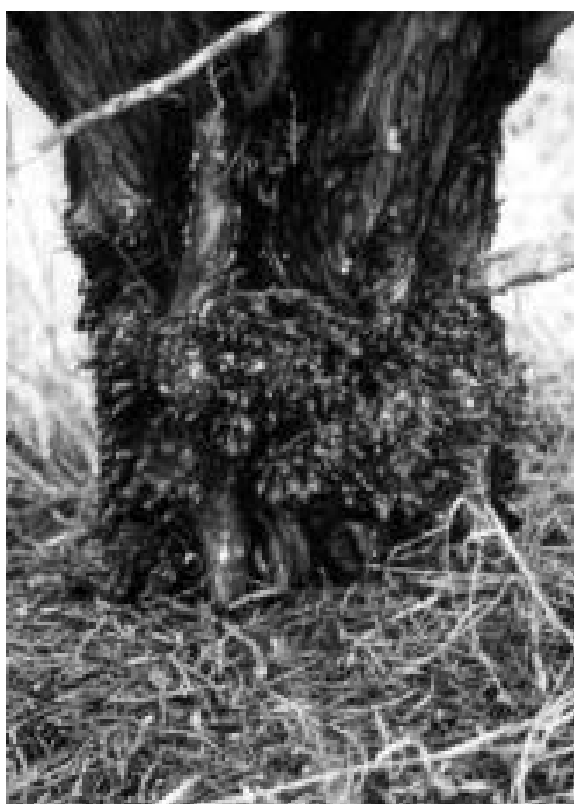

Redberry juniper basal bud zone.

costs. The distance of the pasture from campus also increased the difficulty of predicting weather at the site prior to leaving campus. The presence of a mesquite flat on the north side of Pasture 2 made installation of blacklines much easier than on Pasture 3. The rough, rocky terrain of Pasture 3 required more hours per day due to difficulty of ignition and suppression, and mop up time. The large crew size for Pasture 2 was a result of its close proximity to campus and the desire of students to participate on a burn at this particular ranch.

\begin{tabular}{|c|c|c|c|}
\hline Category & Pasture 1 & Pasture 2 & Pasture 3 \\
\hline Terrain & Smooth & Mixed & Mixed \\
\hline Trips from TTU & 5 & 7 & 13 \\
\hline Blackline & 3 & 4 & 5 \\
\hline Headfire & 2 & 3 & 8 \\
\hline No burning & 1 & 1 & 1 \\
\hline Average number of workers & 11 & 16 & 12 \\
\hline Average hours per day & 12.6 & 10.8 & 17.2 \\
\hline Miles traveled & 3,687 & 5,721 & 10,319 \\
\hline Torch fuel used (gal) & 166 & 112 & 191 \\
\hline Food cost (\$) & 215 & 536 & 864 \\
\hline Actual burn cost/acre (\$) & 3.96 & 3.07 & 6.15 \\
\hline Dozed lines (miles) & 13.1 & 19.3 & 26.0 \\
\hline Estimated dozed line cost/acre $(\$)^{1}$ & 0.61 & 0.88 & 1.14 \\
\hline Estimated burn cost/acre with lines $(\$)$ & 4.57 & 3.95 & 7.29 \\
\hline
\end{tabular}




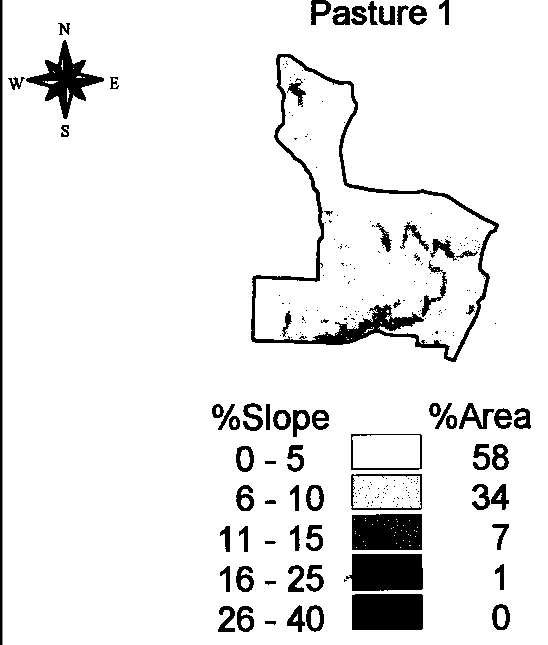

Pasture 2

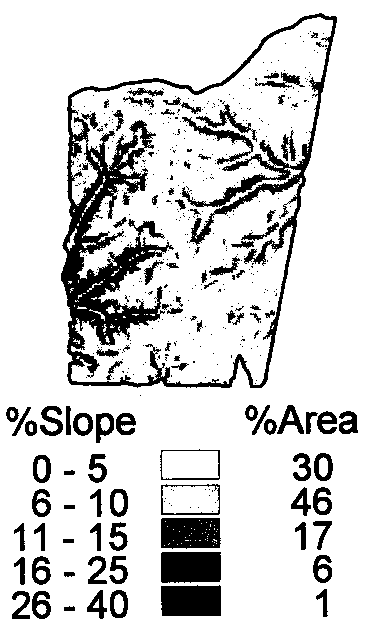

Pasture 3

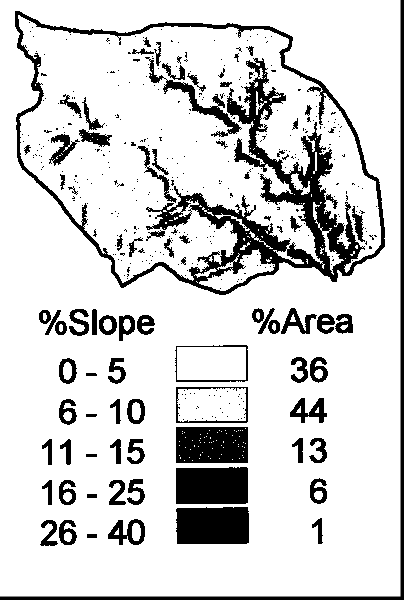

Fig. 2. Slope maps of the pastures generat ed from GPS evaluation and digital ele vation models of the sites.

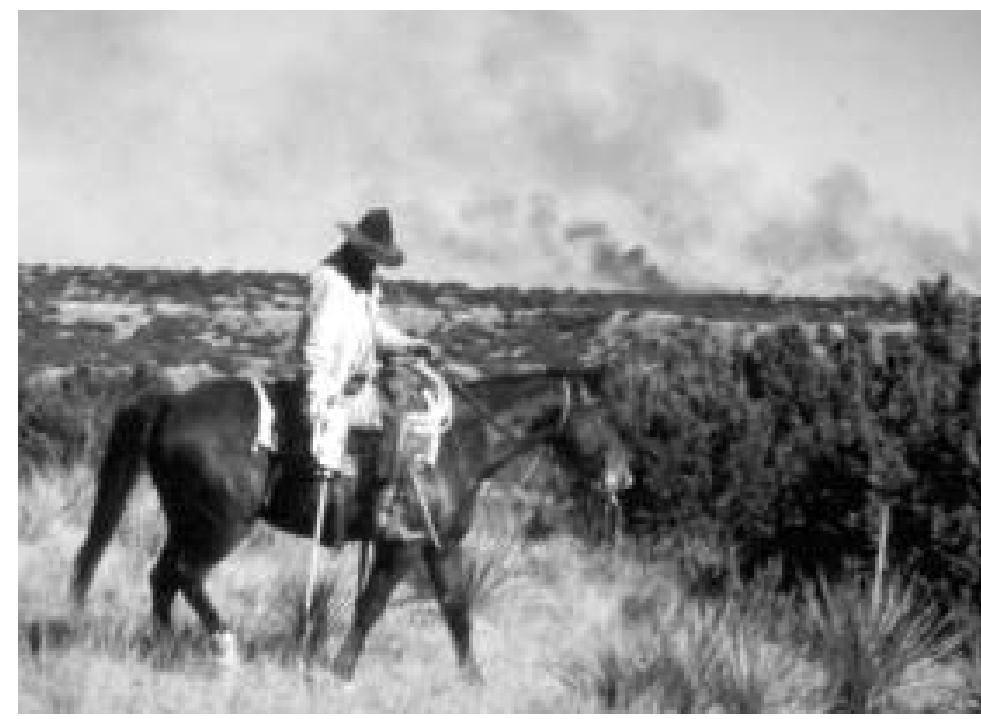

Total miles of dozed lines in each pasture was $13.1,19.3$, and 26.0 for Pastures 1, 2, and 3, respectively, and were estimated to range from 15 to $30 \%$ of the actual burn cost (Table 1). This high cost reinforces the need to plan firelines in less rough terrain. The ranchers for Pastures 1 and 2 owned dozers and employed operators, so installing lines was less costly in these pastures than in Pasture 3. Pasture 1 had the fewest miles of dozed lines due to the smooth terrain of the site, whereas Pasture 3 had the most miles of dozed lines due to the rugged terrain and the need to burn the pasture in seven headfire units (Fig. 2). Pastures 2 and 3 were similar sizes, but Pasture 2 had 147

acres per mile of dozed line, whereas Pasture 3 had 114 acres per mile of dozed line.

Burning juniper communities is hard work and requires many hours of site evaluation to prepare for burning. Additionally, training people to safely and effectively conduct prescribed fires in juniper communities takes time and experience. These results should be useful as guidelines to estimate the cost of prescribed fire application. However, it should be realized that contract burning cannot be conducted for the cost of application if the contractor expects to stay in business. Proper amortization of equipment as well as an adequate profit margin need to be considered in calcu-

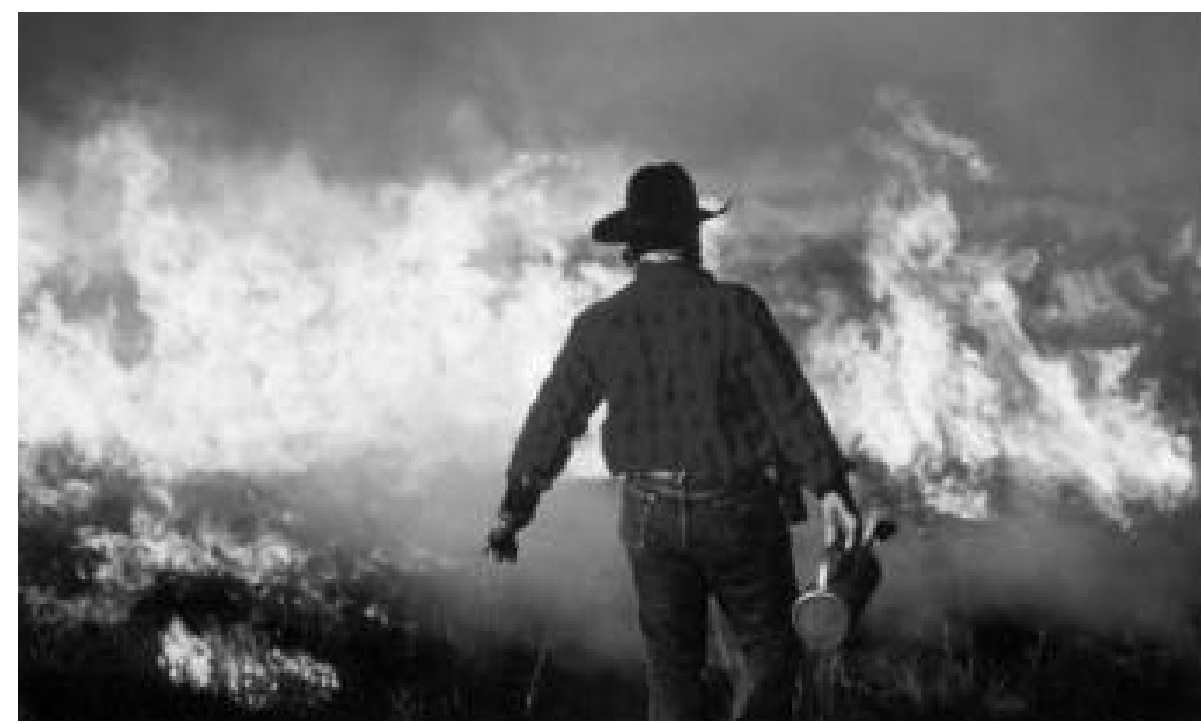

Prescribed burning is inexpensive, but not free. 


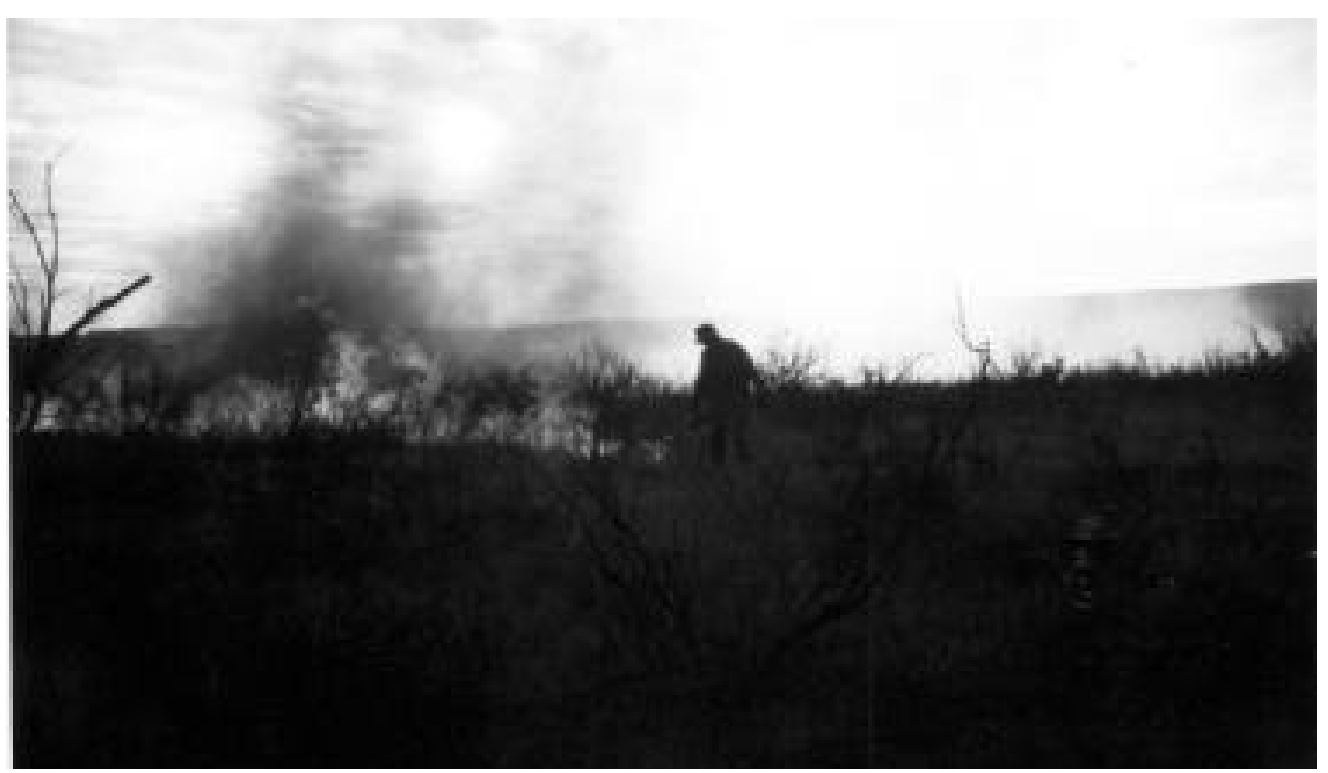

\section{Burning blacklines in redberry juniper.}

lating "full costs". Range professionals recommending prescribed burning to landowners need to remember that prescribed fire application is inexpensive, but not free.

\section{Prescribed Burning Liability in Texas}

A major concern for Texas landowners considering using prescribed fire as a management tool is liability. Although most agricultural policies cover liability from accepted agricultural practices, it is a good idea to contact your insurance company to determine your coverage and the limits of liability under your policy. Legislation passed in the 76th Session of the Texas Legislature limits landowner liability for property damage, injury, or death caused by or resulting from prescribed burning if the prescribed burn is conducted under the supervision of a certified prescribed burn manager. This limitation does not apply unless the certified prescribed burn manager "has liability insurance coverage of at least $\$ 1$ million for each single occurrence of bodily injury or death, or injury to or destruction of property." In the event of an accident, a detailed record of line preparation, notification of authorities and neighbors, permit ac- quisition (if necessary), and a detailed prescribed burn plan including smoke management will provide documentation of proper planning and prescriptions to determine if problems resulted from negligence or an act of God.

Authors are assistant professor, professor, research assistant, professor, and research associate, respectively, Department of Range, Wildlife, and Fisheries Management, Texas Tech University, Lubbock, Texas 79409. Fire Ecology Center Technical Paper 10. Visit the Fire Ecology Center web site at http://www.rw.ttu.edu/fec. 